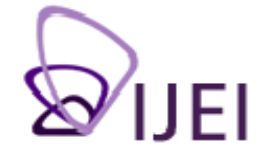

International Journal for Educational Integrity

\title{
A preventative approach to plagiarism: An empirical study of a first-year unit for under- graduates
}

\author{
Sandy Darab \\ School of Arts and Social Sciences \\ Southern Cross University, Australia \\ sdarab@scu.edu.au
}

Keywords: plagiarism, risk-avoidance, ethics, values, experiential learning

\begin{abstract}
This paper reports on an empirical study into the communications of academic values, codes and conventions within a large-scale foundation studies unit for first-year undergraduates at a regional Australian university in first semester 2005. In this unit, one of the foci was teaching students about issues of plagiarism and assessing how students reflected upon and took up those ethics. The unit's content and its assessment were conducted online. Students engaged in experiential learning within multiple online tasks associated with plagiarism and of direct relevance to unit assessment. Unit design, delivery and assessment involved a cyclic process of action research, which facilitated insights into students' value communications and academic skill development over the semester. A qualitative analysis of students' communications within sequential online assessment tasks and anonymous surveys, as well as the value discourses articulated by students and staff, reveals most students were highly receptive to information on plagiarism and intent upon avoiding it through developing academic skills.
\end{abstract}

\section{Introduction}

Academic integrity is increasingly in the spotlight in contemporary western societies. In Australia, recent public concern about academic standards has been driven by media reports on 'soft marking' of international fee-paying students' work and allegations of students buying examination papers; issues serious enough to warrant investigation by the Independent Commission Against Corruption (ICAC) (Thompson, 2004; Kelly, 2005). While these media reports raised public awareness of academic fraud, they merely added to a growing body of academic literature over the past decade which cites a growth in plagiarism and demonstrates students cheating in examinations (Walker, 1998; Carroll, 2002, p. 13; Marsden, Carroll, \& Neill, 2005). Put simply, plagiarism can be defined as 'passing off someone else's work, whether intentionally or unintentionally, as your own for your own benefit' (Carroll, 2002, p. 9).

The reported rise in plagiarism has been linked to the advent of the Internet and the World Wide Web and the freedom of access students have to cut and paste the electronic work of others (Morgan, Dunn, Parry, \& O'Reilly, 2004). Students can log onto a number of sites on the World Wide Web and obtain a tailor-made paper on a whole range of topics (Evans, 2000). However, Errey (2002) argues that plagiarism may not be intentional. Many internet texts used by students serve as a poor model for academic citation and may result in students inadvertently plagiarising (Errey, 2002).

The abundance of literature produced in the United States on plagiarism suggests that students' cheating is a relatively common experience for tertiary educators (Walker, 1998; Cizek, 1999; Lathrop, \& Foss, 2000). A typical example is a survey of 200 American business students which revealed that 80 per cent cheated regularly

The International Journal for Educational Integrity is available online at: http://www.ojs.unisa.edu.au/journals/index.php/lJEl/

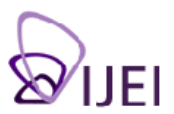


and 20 per cent had plagiarised (Walker, 1998). Similar patterns have emerged in other western countries. In the United Kingdom, a review of undergraduate students' ethics in the mid-1990s revealed that 72 per cent had copied coursework, 66 per cent had plagiarised and 54 per cent falsified references (Franklyn-Stokes, \& Newstead, 1995, p. 159). A recent Australian study showed 81 per cent of undergraduates had plagiarised, 41 per cent acknowledged cheating in an examination and 25 per cent had fabricated references (Marsden, Carroll, \& Neill, 2005, p. 8).

Multiple factors associated with structural, temporal and cultural changes are suggested as contributing to increased plagiarism. The upward credentialing in the labour market has impacted significantly upon graduate careers and students' expectations of their achievements within higher education (Lindberg, 2005). McDowell and Brown (2001 as cited in Carroll, 2002) argue that plagiarism happens because many students now feel pressured to achieve a high grade point average degree to improve their career prospects. The widening staff:student ratio, however, limits the time staff can spend discussing writing practices and dealing with students on an individual basis (O'Donoghue, 1996).

In a study of students' responses to why they had plagiarised, the major reason given was an over commitment to external activities such as work, sport and socialising and 'cheating in desperation when the workload becomes unmanageable' (Zobel \& Hamilton, 2002, p. 25). The term 'over commitment' is applicable across the broader undergraduate population and often involves responsibilities that are not negotiable. Most higher education students today have responsibilities of paid employment and some have heavy caring responsibilities, which require significant time commitments; and many struggle to find sufficient study time (Kember, 1999; Darab, 2005). The end result, however, is not always plagiarism. Studies show that many students worked hard to slot their study time around their responsibilities and sacrificed sleeping time and socialising for study (Kember, 1999; Darab, 2005). Time pressures, a heightened concern over grades, and fewer opportunities for individual assistance are all argued as contributing to students cheating but the strong ethics of some groups of students suggests that if plagiarism is extensive, it might not always be a moral issue.

Some theorists point to the significant rise in the number of overseas students studying in western countries and the differing cultural perceptions they may hold toward plagiarism (Hayes \& Introna, 2003). However, Errey's (2002) study in the United Kingdom found that international students were familiar with rules of plagiarism from their own country and were aware of the British rules but as non-native English speakers they struggled to enact them in written coursework. The incidence of plagiarism does not necessarily mean a decline in ethics; it may reflect a widespread deficit in learning and communication skills for domestic, as well as international students (see Carroll, 2002; Briggs, 2003).

Concerned with preserving their reputations and maintaining their enrolments in the competitive tertiary sector, universities have responded by refining their integrity policies and making explicit the penalties for plagiarists (Briggs, 2003). At the same time, universities have also been pro-active in approaching plagiarism as a learning and communication problem and implementing foundation studies to teach first-year undergraduates disciplinary knowledge and skills.

This paper reports on a study about the pro-active approach taken in one foundation studies unit which adopted the online environment to teach students about plagiarism. The aim of the study was to examine students' learning about ethics at an introductory stage. The first-year core unit, 'Learning and Communication', had its inaugural delivery in first semester 2005 at a regional Australian university. The unit was delivered to a large student cohort $(n=784)$ who represented multiple Schools across multiple campuses, including offshore, as well as external enrolments. Distance students made up almost half the student population $(n=380)$. The unit and its assessment focused upon online and experiential learning to help students develop disciplinary skills, as well as knowledge, within a medium associated with increased 
plagiarism. Online pedagogy, curriculum and assessment were aligned to promote and support a student-centred rather than teacher-centred learning environment. Multiple online activities associated with plagiarism were embedded in the unit content; and students' online participation was encouraged by including their learning experience as part of their assessment. This paper will critically discuss the communications and take up of academic and ethical values within the Learning and Communication environment over the semester. Discussion will centre upon students' communications within the context of online assessment tasks and anonymous survey feedback, as well as the value discourses articulated by students and staff within the learning environment.

\section{Online Learning: pedagogy, curriculum and assessment}

In this unit, the online learning environment was utilised to facilitate experiential learning and help establish habits of ethical practice. Gibbs (1992) argues that experiential learning or learning by doing encourages a high level of involvement, which is likely to motivate students and raise awareness of their existing knowledge base. Students were expected to participate in online tasks involving interactive tutorials, exercises, and quizzes mirroring the content of the unit - learning, research and academic writing. For example, students were directed to the university's online plagiarism policy and to paraphrasing and referencing activities in relation to avoiding plagiarism. In the cyclic process of experiential learning, students were to critically reflect upon their learning, then describe and document it in their Learning Portfolio, so that they could use that understanding to inform the way they approached their next online activity (Gibbs, 1992). As Schon (1987) explains, reflective practice involves understanding learning as an iterative process that entails both action and learning from that action.

This unit also attempted to foster a deep approach to learning through its assessment. According to Marsden et al. (2005) plagiarism is more prevalent in assessment tasks requiring surface rather than deep approaches to learning (Marsden et al., 2005). Gibbs (1992) suggests that students are more likely to take a deep and varied approach to developing skills, if they have a sense of purpose, an awareness of task requirements and flexibility in meeting those requirements. In a bid to make learning experiences meaningful and to activate higher-order thinking skills, unit assessment was integrated with students' performance of authentic tasks and the associated processes in which they engaged (McLoughlin \& Luca, 2001). For example, students attempted activities in a series of online library tutorials which addressed matters such as researching using online library databases and full-text journals, researching using the Internet, and how search engines differ from subject directories. In their first assessment report, they would evaluate their research process and briefly justify their use of search engine and discuss the merits of Internet versus library sources they provided.

Online learning is acknowledged as facilitating a student-centred rather than a teacher-focused approach, but adopting a learner-centred pedagogy requires a new form of assessment focused on learner activity (McLoughlin \& Luca, 2001). In this unit, online assessment was learner-centred and performance-based. The flexibility of the online environment permitted students to be actively engaged in authentic tasks and to demonstrate their progressive learning for the purpose of assessment. The tasks were authentic in two ways. Firstly, students' responses were about their personal experience of each task and secondly, that experience was a real-life problem they faced in managing academic requirements. For example, many students chose to talk about the difficulties they encountered in doing the paraphrasing activities and the strategies they had found useful in developing this skill

Course resources included two prescribed textbooks (Baker, Barrett, \& Roberts, 2002; Summers \& Smith, 2004) and the print-based study guide (Darab \& Phillips, 2005) which provided web sites for relevant online activities and an alternative set of activities for students without Internet access. Students had a choice of one of three 
journal articles available for critical evaluation. These articles included a common focus upon ethical issues in relation to cultural differences and plagiarism (Hayes \& Introna, 2003), work/ life values (Dolan, Diez-Pinol, Fernandez-Alles, Martin-Prius, \& Martinez-Fierro, 2004), and cross-cultural differences in creativity (Westwood \& Low, 2003).

The three assessment tasks: (1) a report, (2) learning portfolio, and (3) critical evaluation of a journal article were customised to reduce the likelihood of plagiarism. Assessment tasks one and three were linked to the same journal article. In the first task, students reported on the research they had conducted in preparation for the third task of writing the critical evaluation essay. Both the progressive structure and individualised responses in the second assessment task, the learning portfolio, minimised the risk of plagiarism. Fail-grade assessments were double marked and resubmit opportunities offered in a first fail-grade assessment. Table 1 depicts only the referencing assessment criterion which was intended to encourage students to model ethical behaviour.

Table 1: Assessment Criteria Relevant to Referencing

\begin{tabular}{|l|l|l|}
\hline Assessment Task & $\begin{array}{l}\text { Final } \\
\text { Weighting }\end{array}$ & Criterion Used \\
\hline (1) Report & $15 \%$ & $\begin{array}{l}\text { - Correct referencing in-text and in reference list } \\
\text { - The ability to integrate references with the dis- } \\
\text { cussion }\end{array}$ \\
\hline $\begin{array}{l}\text { Critical discussion of the credibility of selected } \\
\text { references }\end{array}$ \\
\hline $\begin{array}{l}\text { (2) Learning Port- } \\
\text { folio }\end{array}$ & $50 \%$ & $\begin{array}{l}\text { - Correct referencing format in-text. } \\
\text { - Precise referencing format in annotated bibliog- } \\
\text { raphy }\end{array}$ \\
\hline $\begin{array}{l}\text { (3) Critical Evalua- } \\
\text { tion of Journal Arti- } \\
\text { cle }\end{array}$ & $35 \%$ & $\begin{array}{l}\text { - Correct referencing in-text and in reference list } \\
\text { - The ability to integrate references with the dis- } \\
\text { cussion }\end{array}$ \\
\hline
\end{tabular}

Specifically, the Learning and Communication unit seeks to address the identified deficit in ethical values and disciplinary skills at the first-year level. In providing such learning experiences, it was anticipated that staff members in other units would have to spend less time on these issues. The unit incorporates a time-management component and a heavy focus upon cultural differences and ethical issues both in course content and assessment.

\section{Methodology}

The iterative nature of action research made it the most appropriate methodology for this study. Action research methods allow cycles for planning, acting, observing and critically reflecting upon initial curriculum design and impact of delivery (Smith, Thompson, \& Carter, 1999; Dick, 2002). The initial cycle of design and development commenced in second semester 2004 as a cross-school initiative by the School of Commerce and Management and the School of Social Sciences. The design involved collaboration with an educational designer from the university's Teaching and Learning Centre and library staff, as well as ongoing support from Blackboard specialists in the Online Information Systems Team.

The unit was delivered across multiple schools and campuses to 380 distance students and 404 on-campus students and involved a staffing ratio of six and seven tutors, respectively. Table 2 provides details of on-campus students' locations. Six twohour computer labs were held for on-campus students and commenced in week two of the semester. For distance students, three six-hour computer labs were held at two NSW campuses on consecutive weekends and 48 students attended. 
Table 2: On-Campus Students and Staff Location

\begin{tabular}{|l|l|l|l|l|l|l|}
\hline & $\begin{array}{l}\text { NSW Main } \\
\text { Campus }\end{array}$ & $\begin{array}{l}\text { Satellite } \\
\text { Campus A }\end{array}$ & $\begin{array}{l}\text { Satellite } \\
\text { Campus B }\end{array}$ & $\begin{array}{l}\text { Victorian } \\
\text { Campus }\end{array}$ & $\begin{array}{l}\text { Overseas } \\
\text { Campus }\end{array}$ & Total \\
\hline $\begin{array}{l}\text { On-Campus } \\
\text { Students }\end{array}$ & 129 & 122 & 68 & 29 & 56 & 404 \\
\hline $\begin{array}{l}\text { On-Campus } \\
\text { Staff }\end{array}$ & $\ldots 2$ & .2 & 1 & 1 & 1 & 7 \\
\hline
\end{tabular}

This study represents the cycle involved in the delivery, observation and critical evaluation of the unit in first semester 2005. One strength of action research methodology is that it facilitates the correction of obvious anomalies concomitant with delivery. However, it is in the current cycle of strategic planning that the unit designers have time to critically reflect on the delivery; to code and analyse student and teacher feedback and assessment outcomes; and to develop strategies to further refine the curriculum for future delivery. The analysis focuses upon qualitative data gathered online during semester, which includes students' assessments as submitted for grading (coded as initials) and anonymous survey responses (coded as numerals), as well as markers' feedback.

\section{Sampling Procedures}

To get the broadest possible views of students in this unit, quota sampling was used to ensure each cohort was adequately represented. Three students were randomly chosen from each of the five possible grade categories (F,P,C,D,HD) for their first piece of assessment from each of seven tutors. Five of the tutors represented all the on-campus locations and two tutors represented the domestic distance students. Once a student was selected, their subsequent assessment items became part of a single data set. It is acknowledged that students may not go on to score a similar grade in their next assessment item. In total, 105 data sets were analysed.

\section{Qualitative Analysis}

In keeping with the spirit of qualitative research, the data were not quantifiable and the researcher was not intent upon hypothesis-testing. However, the researcher has provided rich, thick description in an attempt to capture the lived experience of the students and to enable replication of the study (Lincoln \& Guba, 1985). The students' responses are not assumed to provide an objective account of reality but rather to provide a snapshot of their learning experiences in one unit across one semester.

\section{Discussion}

This study sets out to examine learning about ethics at an introductory stage, which precludes making claims about the possibility, or endurance, of acquired values over the long-term. The following discussion centres upon student responses and receptivity to the ethical values and codes of conduct promoted in the Learning and Communication environment. Analysis focuses upon students' demonstrations of disciplinary skills in assessment tasks and the value discourses articulated by students and staff within the learning environment.

\section{Performance in initial assessment task}

The report was the first assessment task due in week 5 . Around two-thirds of students chose the article on alienation and plagiarism (Hayes \& Introna, 2003) to research for their later critical evaluation essay. The work/life values article (Dolan et al., 2004) attracted around 20 per cent of students, many of them business students who expressed interest in the 'work ethic within the globalised environment'. Among the remaining group of students, a number reported their choice on cross-cultural differences as being 'close to the heart of the writer' (Westwood \& Low, 2003). In this task, students were engaging with ethical issues across academia, business, arts and social life. 
In their report, students explained their choice of article and interest in the research area. One student said:

This choice was based on three major factors, firstly, interest in the topic of plagiarism, secondly the written language used in the abstract was easy to comprehend, and thirdly the assumption that the writer could easily relate the points raised by Hayes $\mathrm{N}$. et al. to current issues within Australian Universities (JI:SS).

As well as identifying the value of a clearly written article, the student implies previous knowledge of plagiarism which will serve as a base for future learning. She conveys a sense of confidence in her capacity to apply the knowledge and complete the task. Conversely, most students chose the article as the starting point for learning:

The main reason for choosing this topic is because of Plagiarism. I never knew that copying other people's work was a serious offence. Now that I am aware, I want to do an in-depth research on it in order to know more about it so I can avoid it in my report writing or essay assignments (EE:VD).

Researching the article on plagiarism was a tactical way they could avoid plagiarism in the future and minimise an unexpected risk to study progression. Like this student, many claimed that plagiarism was a relatively new concept of direct and immediate relevance to them and that it was in their best interests to research it. Even with prior knowledge, the topic remained relevant for one student:

The author chose this article as it deals with plagiarism, an issue close to him as throughout the current degree of business, and even more so in his previous degree of Applied Science was an issue that was never fully understood. It is hoped to learn more about this subject through this assignment (JS:JP)

This disclosure serves as a reminder that theoretically students may know that plagiarism is wrong but still be unsure about the ownership of ideas and how to translate them. There is indeed potential for error, particularly when students are beginning to learn how to interpret their readings and translate their concepts into a coherent body of text. This student's online posting also signals differing practices across disciplines in the past and offers some justification for units such as this. It is anticipated that upon completion of this unit, students will have a sound working knowledge of disciplinary skills and values that will reduce the risk of plagiaristic practices and will provide a platform for future learning about academic integrity.

What stood out was in students' reflections was that despite many students having little prior knowledge, the majority of students were aware of plagiarism and concerned that it constituted a 'serious' and immediate risk to be managed. One student at an overseas campus explained:

As this Institute experienced an increased number of students plagiarising last year resulting in a lot of awareness given by lecturers on the issue, I have decided to research the article titled 'Alienation and Plagiarism:... which can be access online at http://www.lums.co.uk/publication (EE:CL).

The message of plagiarism was circulating in multiple discourses across universities. Students and staff generally were keen to minimise the risk of plagiarism. However, this is not to suggest that all students were unaware of plagiarism. For some students, the article simply represented the best choice in a limited range. In the later anonymous online survey, some students expressed a distinct preference for disciplinary-specific material. 'I would much rather learn about economics or a business related subject as the other units (quant analysis, business law and management) are relevant to my degree' $(20677 \mathrm{CH})$. Another student reported, 'while the report and essay were a valuable learning tool, I would have preferred to spend time researching a relevant topic for my major' $(22028 \mathrm{CH})$. 
At this early stage, most students had yet to develop proficiency in referencing skills, particularly in-text, as can be seen in the above student quotes. However, there is abundant evidence in the reports that most students (around 85\%) did attempt to reference their sources and support their arguments, drawing mostly from course resources and online library and academic tutorials that had guided their research efforts. For example, in critically discussing research on the Internet versus the library, a student wrote:

Author's and publisher's credentials were easily identified from WWW sources that were from government or educational domains and from SCU Library catalogue and database sources. When evaluating other WWW sites the author's and publisher's details were either very difficult to identify or were not found at all. It is important to note that reputable publishing houses usually have works processed through an external review process before they are accepted to be published (Baker, Barrett, \& Roberts, 2002), making them very reliable sources of information (JM:TB).

Most students were attempting to act in an ethical manner and markers praised their attempts, as well as offering detailed feedback. Around 10 per cent of students failed and an unusually high number (20\%) declined the opportunity to resubmit. Students reasoned that a resubmit 'was not worth the effort for a few extra marks'. It may be worthwhile to consider increasing the weighting of the task (15\%). Such a step would better reflect the time demands involved and encourage the most at-risk group of students to do the resubmit and further develop their skills.

There was a breach of conduct in this task. One case of plagiarism was reported. Two students submitted identical research reports, ironically, on the topic of plagiarism.

With multiple markers and a large external student cohort, the duplication could easily have gone unnoticed but the students had the misfortune to be allocated to the same tutor. The case was addressed following university procedure. The reports were marked by the tutor and unit assessor, then referred to the Head of School who confirmed a zero grade and informed the students of their rights of appeal. As Briggs (2003) has noted, dealing with plagiarism is a time-consuming and joyless exercise which often ends up alienating students. This case was no exception; the students chose to withdraw from the unit.

\section{Progressive development assessment}

In their Learning Portfolio assessment, students produced a valuable course resource. The assessment provided a site in which students could demonstrate development in academic and online skills, as well as content knowledge, and students were rewarded for their efforts in that any practice they undertook could be submitted for assessment. The assessment was mainly comprised of students' critical reflections on their online experiences. Each online practice had potential to be part of their assessment. Most students did demonstrate increased capacity over the semester to engage in research, critical discussion, and conduct attuned to academic values and codes which is evidenced in the nature of their critical reflections in the Learning Portfolio.

Student attempts to acquire ethical skills are visible in their reflections throughout this task but are particularly strong in the research component. The following quote is exemplary of many students' reflections at this stage:

I learnt in the following website www.library.ualberta.ca/guides/plagiarism/ the ethical issue I have to consider when using someone else work or idea. I learnt that in the increase of internet researches that I have been doing I need to consider the cyber-plagiarism aspect of it because it is easy to commit this offence. The site made me think about my other assignment if I can truly say to myself that I didn't plagiarise. I found it also handy because it had a link that explained the way I can prevent plagiarising the main point that I learnt. 
Whenever I am in doubt it is always best to reference the source (JI:JT).

This reflection offers some support for Gibbs' (1992) belief in experiential learning engaging students at a high level. The student does take a deep approach to learning. She is receptive to the plagiarism messages and is using higher order skills to apply them to her own practices and a task beyond the interactive tutorial. She is adopting strategies to facilitate competency in future work. Like this student, many were working to grasp the complexities of referencing and citation. Another student reported:

Ted Frick (2001) has developed a good tutorial on plagiarism on the Indiana University website. In each example he shows the original source material and an example of a students' work, using the source material. The aspect of this tutorial that I liked the most is the structure of the answers available for selection. Each example has four 'yes - this is plagiarism' options to consider - each with different reasoning. This requires one to think more about why the source has been plagiarised, than a purely 'yes' or 'no' choice usually encourages (TS:Al).

In this posting, the student is comparing and ranking tutorials which suggests a reasonable level of student involvement. Moreover, the student's expressed desire for a mental challenge rather than 'a purely 'yes' or 'no' choice' suggests signs of higherorder thinking in relation to plagiarism. Overall, the students' reflections on their learning experiences, on the ways they tackled problems and which strategies they adopted, allowed valuable insights into learning processes and progress in this unit. In the final position paper, one student wrote:

When I first began this course, my approach was one of stubbornness and fear. I believed that I had all the answers and that the course would just be a matter of learning dates, events etc. I had no idea that my learning capabilities and attitudes would be challenged...My academic writing skills concerned me and there is still some anxiety when I write, as I tend to be very opinionated. However, I am learning that my opinions and perceptions can be expressed but there is a correct way of applying these thoughts academically. Referencing was a huge issue for me until I researched plagiarism and developed an understanding of the complexities involved. I had an attitude in this area and thought it was all a waste of time until I realised the importance of acknowledging another person's work (JW: JP).

Personal disclosures of insecurities and perceived weaknesses that had to be overcome in order to facilitate learning about plagiarism were quite common in this assessment. In their critical reflections, female students were more inclined to focus upon internal factors affecting learning than their male counterparts. Young male students up to their mid-20s were the least inclined cohort to discuss personal strengths and weaknesses and the most reluctant to use words such as 'l' and 'my' in their postings. The following posting provides a good example:

The online Library tutorial (SCU 2005) for topic analysis was great, as it looked at separating the key concepts of a question and how this can help a student realise what the assignment actually focuses on. The citation tutorial also was very effective and useful, presenting both APA and Harvard forms of referencing in text, journal, internet site, and other forms used within university level referencing. This too would help students within their first year of doing a university degree. However, the internet search tutorial was very basic and only focused on the workings of one search engine, instead of a couple different ones. I would only recommend this for people who are completely computer illiterate. (BD: JW).

This student did critique the online tutorials in terms of their use value to undergraduates but he made no attempt to relate their usefulness to his own learning 
experience. Even the use of the word ' $l$ ' in this posting involves a recommendation relevant to the learning experiences of others. While his critique suggests that he is actively involved in the online tutorials, his preference for the third person limits his capacity to demonstrate his progression in the learning process. In contrast, many other students took a problem-based approach to learning in this assessment which is exemplified in the following quote:

I feel I am still not $100 \%$ sure of how to reference an Author's work when it appears in a different Author's work. Do you put: such and such, such and such (John Smith, 2000. in John Doe, 2004, pp. 1)?? ...NB: I completed the My SCU library and general computer tutorials after I had typed this section. My concerns in the above sections had been resolved through information provided in these tutorials. I now feel competent in both situations (JI:KW) [emphasis in original].

There is a clear indication of the unit's learner-centred approach in this student's post note (McLoughlin \& Luca, 2001). This assessment focuses solely on his learning experiences and progressive development and within this context, the student feels comfortable to demonstrate his learning rather than give a polished performance. That he acknowledges his difficulty and requests clarification suggests the student regards this assessment as a legitimate learning opportunity. Moreover, he effectively utilises the opportunity by sourcing his own answers and demonstrating progression in his learning. In undertaking this process, he displays increased confidence in his capacity for learning, as well as for referencing. Like this student, many showed signs of taking a deep approach to learning in this assessment in terms of high levels of motivation, awareness of their existing knowledge base, a sense of commitment to, and 'ownership' of their learning (Gibbs, 1992). Despite variation in learning styles and the rates of skill development, at the end of this unit most students conveyed a similar sense of confidence in the online survey, claiming they had developed 'a heap of skills' in this unit including 'some good critical analysis and time management skills \& I have a great understanding of plagiarism and referencing now' (26466U).

Students' efforts were reflected in their marks and the majority did very well in this assessment. The main reason students failed was because they did not complete each section of the task. Most frequently students omitted the annotated bibliography and other evidence section, which were not undertaken as part of their weekly practices. Students who received resubmit invitations reported such omissions both as a failure to check the marking criteria and a lack of time to go back over their Learning Portfolio postings and extract sources. What is of interest here is that the personalised nature of the assessment worked against students 'cheating in desperation' when the submission date loomed (Zobel \& Hamilton, 2002, p. 25). There was no web site offering ready-made papers on an individual student's learning experience in this unit. Almost all resubmit opportunities were taken up in this heavily weighted task (50\%). There were no reports of plagiarism. Markers reported students were consistently referencing sources, though often incorrectly in this task, tending to include websites in-text instead of the author-date system. It was suggested that the large number of websites embedded in the study guide had served as a poor model for in-text referencing.

\section{Students' appreciation of ethical issues}

The amount of time needed between the second and third assessment was longer than anticipated in design. There was insufficient time between these assessment tasks to allow students to receive and incorporate markers' comments on incorrect referencing. Apart from the inclusion of websites in-text, the most common referencing problems were associated with style deviation - mixing style of brackets, commas, full-stops, incorrect use of 'et al' and so on. Perhaps these mistakes by students were due to the nuances in author-date disciplinary styles across different schools because markers also reported some confusion and frustration with these style variations. Nonetheless, in the third critical evaluation assessment, most 
students were consistently paraphrasing and referencing sources to an appropriate standard. Most students were able to demonstrate that they had met the unit's learning objectives of developing skills and knowledge in research, referencing, critical thinking and academic writing. For the majority of students, plagiarism was no longer an unknown issue or a major concern.

Within the students' critical evaluations, there is ample evidence of value communications. Many were engaged in exploring and discussing ethical complexities beyond markers' expectations in this task. The task required students to examine both the content and the structure of the article. Since the unit was written for first-year undergraduates, it was expected that students would use their research training and writing techniques to discern if the authors had stated the aim of the study, defined key concepts, backed up their arguments, used credible sources, provided clear tables and so forth. For example, it was anticipated that students would identify Hayes and Introna's (2003) failure to define the key concept of plagiarism. What was unexpected, however, was the large number of students who were highly critical of Hayes and Introna's (2003) perceived failure to clearly articulate the link between ethics and plagiarism. The international students studying in Australia were particularly scornful, as the following quote exemplifies:

Regard of definition of plagiarism, Hayes and Introna raised the argument about the root of plagiarism came from the culture confliction. They use survey and referencing from other literatures to support their points. They pointed out the reason of plagiarism, including English language problem, culture confliction and inability to complete the research. However, there is one very important reason about plagiarism that Hayes and Introna mention but not express much clearly: the root of plagiarism is ethic problem. The point about the reason of plagiarism that Hayes and Introna made in the article cannot explain why UK student also cheat. Because English is UK students' mother tongue, they have absolutely no problem in language as well as no culture confliction with the lecture method. Furthermore, if it is the student's inability to complete the studying task, how can they enter the university? (SD:YY).

The student is taking a deep approach in questioning the assumptions of the research, making a strong counter-argument of significant personal relevance and offering a contribution to a broader ethical debate. The cultural difference focus on plagiarism, he says, distracts attention from what is fundamentally an ethics problem and must be considered within that context if it is to be understood. He calls into question the explanatory power of an approach which ignores that plagiarism is a cross-cultural phenomena and a 'general moral problem in universities'. He rejects an approach which has the potential to associate his cultural difference with an immoral act. So did the other international students critiquing this article. In general, research does not support the notion that cultural differences increase the likelihood of plagiarism among international student groups (Hinton, 2004). International students are aware of rules about plagiarism from their own country but, as can be seen in this study, a lack of formal English and disciplinary skills often hinder students' efforts to enact requirements (Carroll, 2002). Domestic students were also sceptical about the value of Hayes and Introna's (2003) research. To quote one student:

Hayes and Introna (2003) have failed to mention that plagiarism is an immoral action in any field in the world. For example, Australia's best-selling author, Jessica Adams, has been accused of plagiarizing noted crime writer Agatha Christie....Her reputation and status are destroyed because she has been unethical. This cautions us that if we do plagiarise, it may not only destroy our study life, it will also destroy our future work prospects. (DN:WJ).

This student articulates a moral discourse that highlights the serious long-term risk plagiarism entails for students. She too cites the cross-cultural prevalence of plagiarism and the need to address it as an ethical dilemma if the risk is to be minimised for students. There are many examples in the students' critical evaluations 
of similar levels of student involvement and discussions of values in relation to research methods. To quote one student's critique of his chosen article:

When undertaking the questionnaire the students were 'pressured' into completing the task by having someone near the exit, making it 'normatively difficult to leave the room without handing a questionnaire in' (Hayes \& Introna, 2003). Such pressure may result in falsified responses under fear from persecution or entrapment. Also, with small sample sizes the responses could easily have been linked to individuals, even to the point where only one Chinese representative was in attendance for the focus groups (DM: DN).

Just like this student, many others also called into question the methodology in the Hayes and Introna (2003) study. In particular, students were concerned about the reliability of the questionnaire as a measurement technique, the representativeness of the focus groups and the validity of the study in terms of inferring whether students would plagiarise in their studies. Students who critiqued the article on the business students, also raised doubts about the research methods:

The results within the journal article on Spanish business students (Dolan et al., 2004) presented tables and statistical data of the work and life values which were answered by the sample. Darab and Phillips (2005) write that when analyzing the results of a journal article you should examine "the fit between the methodology and the results" (Darab \& Phillips, 2005, p. 418). Within the journal article on Spanish business students it is hard to identify the fit due to the simplicity and lack of detail within the methodology. The methodology was short and not even a full page. The methodology stated that in measuring the work values their questionnaire had been inspired by Donald Super's 'Work Values Inventory', but they did not include a copy of what Donald Super's work values were. Within the result section of the journal article there are tables of statistical data on work and life values. These values fit within the 16 life values and 17 work values that were mentioned in the methodology. The results also include tables and statistical data along with a written explanation of the findings, which is beneficial because it is easy to read and understand (KD:SD).

In the above quotations it is clear there was considerable variation between students in terms of their analytic and written skill development. While such variation is to be expected, most students in this unit showed a heightened awareness of plagiarism in questioning the assumptions of researchers, their research instruments and approaches. They also demonstrated competency in writing and referencing skills sufficient to pass this unit. However, the emphasis is upon the students choosing to enact disciplinary requirements in future work. There is no guarantee that students had internalised the ethics that were communicated in this unit. In this final assessment, one case of plagiarism was detected and, again it was officially dealt with. Resubmit offers at this stage of the semester mostly involved students' failure to critique the article, choosing instead to write a well-referenced essay on the topic. Some of these failed essays were very general - particularly on the topic of plagiarism - and it is possible that they were not the student's own work. Alternatively, students may have misunderstood the nature of this assessment task.

\section{Conclusion}

This study provided insights into value discourses, ideas, beliefs, and concerns in relation to students' learning progression over one semester. It cannot be inferred that raising awareness of ethics will result in students internalising these values as part of their own moral code. However, it can be argued that the level of academic skills students developed in this unit will equip them to be ethical in their academic practices, if they choose to enact them.

We have seen many examples of students engaging with issues of academic integrity and communicating academic values within the learning environment. There is also 
evidence of students' progressive development in modelling ethical conduct and demonstrating academic skills within assessment tasks. The success of the communications may be gauged by students' strategic attempts to avoid plagiarism. Strategies included using higher order skills to reshape their practices, applying knowledge to tasks beyond this unit, and sourcing their own answers. The heavy focus upon plagiarism in course and assessment content meant that students had to engage with ethical considerations to some extent. Many excelled and took a deep approach in investigating and analysing ethical concerns in relation to the methodology adopted by researchers. Students' receptivity to the communications of value discourses was high when the topic was of personal and direct relevance. Many students demonstrated preferences for discipline-specific material - both in their choice of the work ethics article and in survey comments - that are not easily addressed within the customised critical evaluation task for two reasons. Firstly, tutors' limited reading time prohibits expanding the range of discipline-specific articles. Secondly, the organisational constraints involved in this large-scale unit, with different starting times for different campuses, do not readily facilitate allocating tutors on the basis of students' choice of article.

I would argue that incorporating a requisite skills training program within the online environment provided a useful conceptual framework to facilitate students' understandings of academic integrity and disciplinary practice, as well as ample online learning opportunities so that students could apply those understandings. I would also suggest that aligning the curriculum and assessment to support a student-centred environment yielded evidence both of students' taking a deep approach to learning and of their progression in the learning process. In keeping with action research methodology, the current cycle of curriculum development allows the opportunity to address the weaknesses that have been identified in this paper.

\section{Author Biography}

Sandy Darab is a lecturer at Southern Cross University in the School of Social Sciences. She teaches sociology both at the under-graduate and post-graduate level. She has been involved in designing, developing and delivering the large-scale foundation studies unit for first year students which is the focus of this paper. In addition to her ongoing interest in pedagogy, curriculum and ethics, Sandy's research focus is upon time usage and issues of social justice. At present, she is researching the time patterns of first-year university students'. Sandy is also part of a research team investigating the WorkChoices and Welfare to Work reforms and their effects in regional NSW.

\section{References}

Baker, E., Barrett, M., \& Roberts, L. (2002). Working communication. Brisbane: Wiley. Briggs, R. (2003). Shameless! Reconceiving the problem of plagiarism. Australian Universities Review, 46(1), 19-3.

Carroll, J. (2002). A Handbook for deterring plagiarism in higher education. Oxford: Oxford Centre for Staff and Learning Development.

Cizek, C. J. (1999). Cheating on tests: How to do it, detect it and prevent it. Mahway, $\mathrm{NJ}$ : Lawrence Erlbaum.

Darab, S. (2005). Time and study: Open Foundation female students' integration of study with family, work and social obligations. Australian Journal of Adult Learning, 44(3), November.

Darab, S. \& Phillips, J. (2005). EDU10235 Learning and communication study guide. Lismore: Southern Cross University.

Dick, B. (2002). Doing good action research. Paper presented at Southern Cross University seminar, 18 February. 
Dolan, S. L., Diez-Pinol, M., Fernandez-Alles, F., Martin-Prius, A. \& Martinez-Fierro, S. (2004). Exploratory study of within-country differences in work and life values: The case of Spanish business students. International Journal of Cross Cultural Management: CCM, 4(2), 157-81.

Errey, L. (2002). Plagiarism: Something fishy? Or just a fish out of water? Teaching Forum, 50, 17-20.

Evans, J. (2000). The new plagiarism in higher education. Interactions, 4(2), Summer. Retrieved February 2006 from http://www.warwick.acukETS/interactions/vol4no2/ evans.html

Franklyn-Stokes, A. \& Newstead, S. E. (1995). Undergraduate cheating: Who does what and why? Studies in Higher Education, 20(2), 159-172.

Gibbs, G. (1992). Improving the quality of student learning. Bristol: Technical and Educational Services.

Hayes, N. \& Introna, L. (2003). Alienation and plagiarism: Coping with otherness in our assessment practice. Working Paper for Lancaster University Management School, Online Version. Retrieved December 17, 2004, from http:// www.lums.co.uk/publications/abstract/239/

Hinton, L. (2004). Plagiarism: Learning from our challenges, Studies in Learning, Evaluation, Innovation and Development, 1(1), 37-46.

Kelly, M. (2005, July 11). No evidence of corruption. The Newcastle Herald.

Kember, D. (1999). Integrating part-time study with family, work and social obligations. Studies in Higher Education, Abingdon, 24(1), 109-124.

Lathrop, A. \& Foss, K. (2000). Student cheating and plagiarism in the Internet era: a wake-up call. Englewood: Libraries Unlimited.

Lincoln,Y. \& Guba, E. (1985). Naturalistic inquiry. Beverley Hill: Sage.

Lindberg, M. (2005). Is it worth being 'traditional' in an era of mass individualization? Higher Education in Europe, 30(3-4), 385-398.

Marsden, H., Carroll, M., \& Neill, J. T. (2005). Who cheats at university? A self-report study of dishonest academic behaviours in a sample of Australian university students: Australian Journal of Psychology, 57(1), 1-10.

McLoughlin, C. \& Luca, J. (2001). Quality in online delivery: what does it mean for assessment in E-learning environments? In Meetings at the Crossroad: Proceedings of the 18th Annual ASCILITE Conference, Melbourne, 427-434.

Morgan, C., Dunn, L., Parry, S., \& O'Reilly, M. (2004). The Student Assessment Handbook. London: Routledge Falmer.

O'Donoghue, T. (1996). Malaysian Chinese students' perceptions of what is necessary for their academic success in Australia: A case study at one university. Journal of Further and Higher Education, 20(2), 67-80.

Schön, D.A. (1987). Educating the reflective practitioner. San Francisco: JosseyBass.

Smith, D., Thomson, T., \& Carter, R. (1999). Breaking down the barriers: Using action learning to facilitate effective cross-cultural communication. International Education, 3(2), 1-9.

Summers, J. \& Smith, B. (2004). Communication skills handbook: How to succeed in written and oral communication, (Revised edn). Brisbane: Wiley.

Thompson, M. (2004, September 18-19). Hard to credit. The Sydney Morning Herald.

Walker, J. (1998). Student plagiarism in universities: What are we doing about it? Higher Education Research and Development, 17(1), 89-106.

Westwood, R. \& Low, D. R. (2003). The multicultural muse: culture, creativity and innovation. International Journal Cultural Management, CCM, 3(2), 235-260.

Zobel, J. \& Hamilton, M. (2002) Managing student plagiarism in large academic departments. Australian Universities Review, 45(2), 23-30. 